\title{
Conceptual design of the Polarized Electron Ion Collider at Brookhaven National Laboratory
}

\author{
John Skaritka ${ }^{1}$ \\ Brookhaven National Laboratory, \\ Upton, NY. 11973, USA \\ E-mail:skaritka@bnl.gov
}

\author{
Erdong Wang ${ }^{1}$, Ferdinand Willeke ${ }^{1}$, Robert Lambiase ${ }^{1}$, Wei Lui ${ }^{1}$, Vadim Ptitsyn ${ }^{1}$ \\ Omer Rahman', \\ Brookhaven National Laboratory, \\ Upton, NY. 11973, USA
}

To facilitate the SAC 2015 Long Range Plan for Nuclear Science: a high-energy highluminosity polarized Electron-Ion Collider (EIC) as the highest priority for new facility construction following the completion of FRIB. Brookhaven National Laboratory (BNL) is proposing to build a high luminosity electron-hadron collider called e-RHIC which incorporates a new electron synchrotron with the existing Relativistic Heavy Ion Collider (RHIC). A low risk conventional technology based design is being adopted for the majority of the accelerator components. The e-RHIC electron source will produce a highly polarized beam current of up to $50 \mathrm{~mA}$ with $>80 \%$ polarization at an energy of up to $18 \mathrm{GeV}$ with a luminosity $>1034 \mathrm{~cm}-2 \mathrm{~s}-1$. The prototype e-RHIC beam source is currently under development at BNL and Stony Brook University. This paper presents a conceptual design of the e-RHIC machine, how polarized beam will enhance the physics program and plans to address the remaining challenges associated with the construction of e-RHIC. In order to construct a future electron ion collider with high luminosity, a high average current and high bunch charge polarized electron source is under development at Brookhaven National Laboratory. We present the R\&D plan for achieving the required charge and current in the polarized eRHIC gun. The plan involves developing a large single cathode gun to generate $5.3 \mathrm{nC} /$ pulse and up to $6 \mathrm{~mA}$ polarized electron beam. We report the status of the large cathode prototype gun development, the beam line design and plan for measuring gun charge lifetime for high charge, high current operation.

XVII International Workshop on Polarized Sources, Targets \& Polarimetry

16-20 October 2017

Kaist, South Korea 


\section{Introduction}

In its long-range plan for nuclear science, the U.S. Nuclear Science Advisory Committee (NSAC) has recommended, "a high-energy high luminosity polarized electron ion collider (EIC) as the highest priority for new facility construction following the completion of FRIB". [1] Brookhaven National Laboratory (BNL) proposes the future EIC using the onsite RHIC facility called eRHIC and to carry out supporting R\&D on critical design issues. The ERL-based design provides a more cost effective solution for eRHIC. The top R\&D priority for the ERL based scheme is establishing a high current polarized electron source.

\subsection{The Physics Case and the question's to be answered by an EIC}

The EIC will enable novel measurement of nuclear structure and dynamics by using polarized electron and hadron beams as unparrelled diagnostic tools for the study of nuclear spin physics to advance our understanding of the "nucleon's inner landscape".

\subsubsection{How is the proton and neutron spin of $1 / 2$ composed by its constituents?}

We don't know how the proton spin is composed. We know that the simplist assumption of quark spin configuration was proven wrong in 1987. Since then, despite many efforts, this remains an unresolved question. The EIC with its two colliding polarized beams will shed light on this mystery.

\subsubsection{How are the gluons spatially distributed in the nucleons?}

There are hints that the high stability of the proton is due to the fact that the gluons are concentrated near the surface of the nucleon. An EIC will enable us to measure these as well as explore the mysteries underlying the structure of the quark gluon plasma.

\subsubsection{How does the gluon density saturate?}

Earlier lepton hadron scattering experiments showed that the density of the gluons increases dramatically if they carry smaller fraction of the nucleon's momentum. First principles tell us this density increase must saturate, but we do not know when and how. Is saturation related to other unexplained phenomena? Electron-Ion collisions at high collision energies will make a significant step forward to understanding.

Accelerator based nuclear physics experiments and studies in the field have led to a strong and exciting physics case of the EIC which is acknowledged not only in the Nuclear Physics community but has also stirred interest in the High Energy Physics Community in particular in the Deep Inelastic Scattering Community, as fundamentally new physics could emerge from an EIC physics Program. 


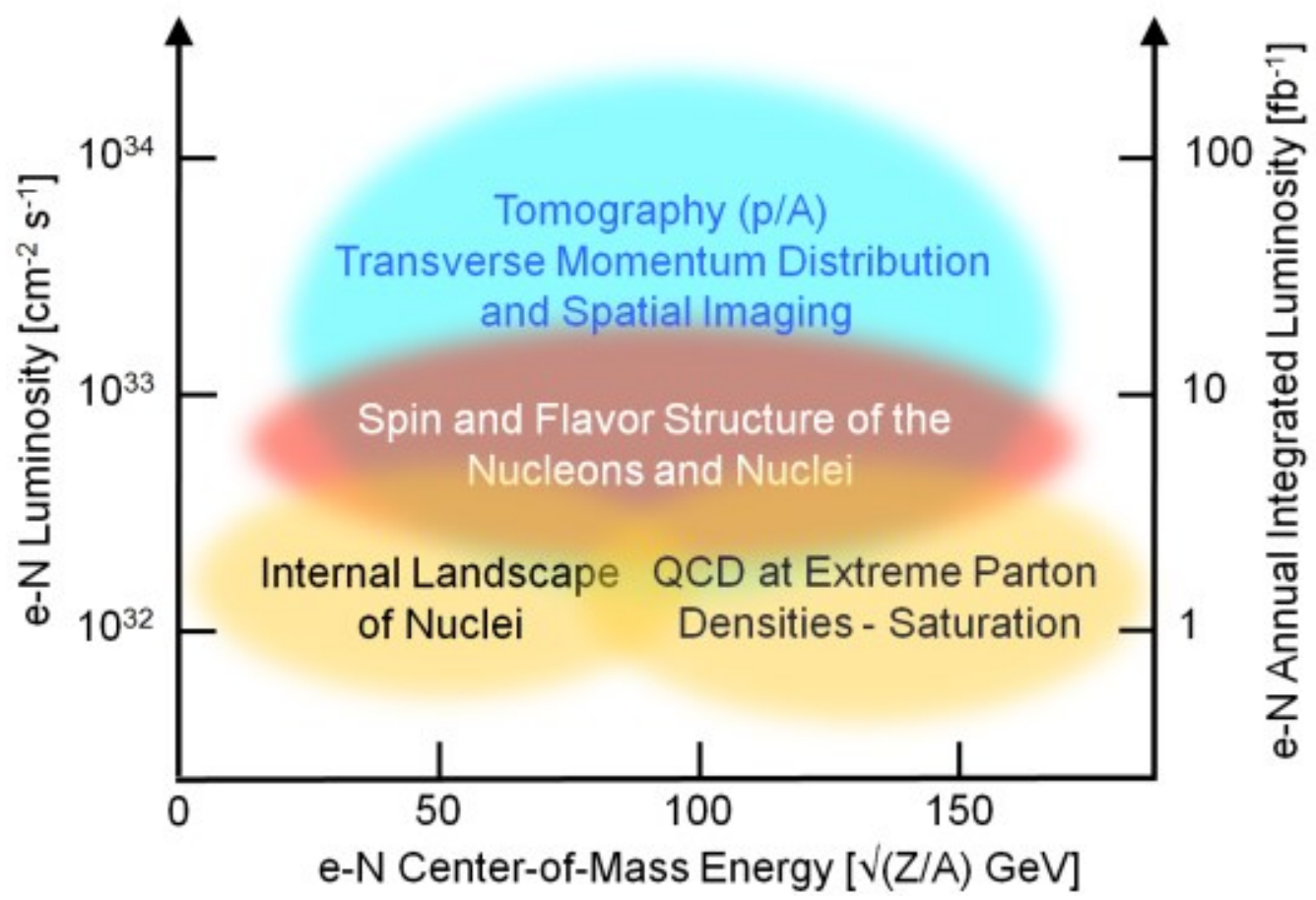

Figure 1 The Physics Reach of the EIC

\section{EIC Requirements}

Large Luminosity, scattering cross sections are small $\rightarrow \mathrm{L}=\left(10^{33}-10^{34}\right) \mathrm{s}-1 \mathrm{~cm}-2$, large average luminosity with a large range of center of mass energy.

$\mathrm{Ecm}=2 \sqrt{\boldsymbol{E}_{\text {hadron }} \cdot \boldsymbol{E}_{\text {electron }}}=(30-140) \mathrm{GeV}$.

Electrons energy range will be (5-18) GeV and protons: (50-275 GeV), and corresponding Ion Energies up to $100 \mathrm{GeV} /$ nucleon. There will be a large span of ions (from light to heavy). Large detectors will be used with forward, backward acceptance, in particular for forward scattered Hadrons at small angle. The system will provide fast precision, measurements bunch-by bunch luminosity and polarization. The two beams must be longitudinally spin polarized in collisions, $70 \%$ hadrons, $80 \%$ electrons, and all combinations of spin orientations present in one fill.

\section{3. e-RHIC Design Concept:}

The major part of a future EIC already exists within the RHIC facility. The BNL version of the EIC makes use of the existing RHIC accelerator complex, which constitutes more than $2 / 3$ of the cost of the eRHIC facility.

eRHIC will use the Yellow Ring and parts of the Blue Ring leaving Most of RHIC will remain untouched with RHIC beam parameters already satisfying eRHIC requirements. Some changes in the straight sections are required to maintain a constant revolution time independent of energy. Based on the existing Relativistic Heavy Ion Collider (RHIC) with up to $275 \mathrm{GeV}$ polarized protons An additional electron storage ring with $(5-18) \mathrm{GeV}$ in the RHIC tunnel will store up to $2.7 \mathrm{~A}$ of electron current - 1320 bunches per ring similar to B-Factories The e-RHIC RF system will have an administrative power limit of $10 \mathrm{MW}$ maximum RF power. 
Flat proton beam: $2.4 \mathrm{~mm}$ horizontal, $0.1 \mathrm{~mm}$ vertical will have proton bunch intensities moderate: $0.75 \cdot 1011$ can be achieved in RHIC with on-energy polarized electron injector (up to $18 \mathrm{GeV}$ )

The system will be designed for Peak Luminosity: $>\mathbf{1 . 1} \times \mathbf{1 0}^{\mathbf{3 4}} \mathrm{cm}^{-\mathbf{2}} \mathrm{sec}^{-1}$ with full energy polarized electron injector. Two options have studied in detail, An Energy Recovery Linac Ring (Linac Ring),"LR"and Rapid Cycling Synchrotron (RCS) and Storage Ring option (Ring Ring), "RR

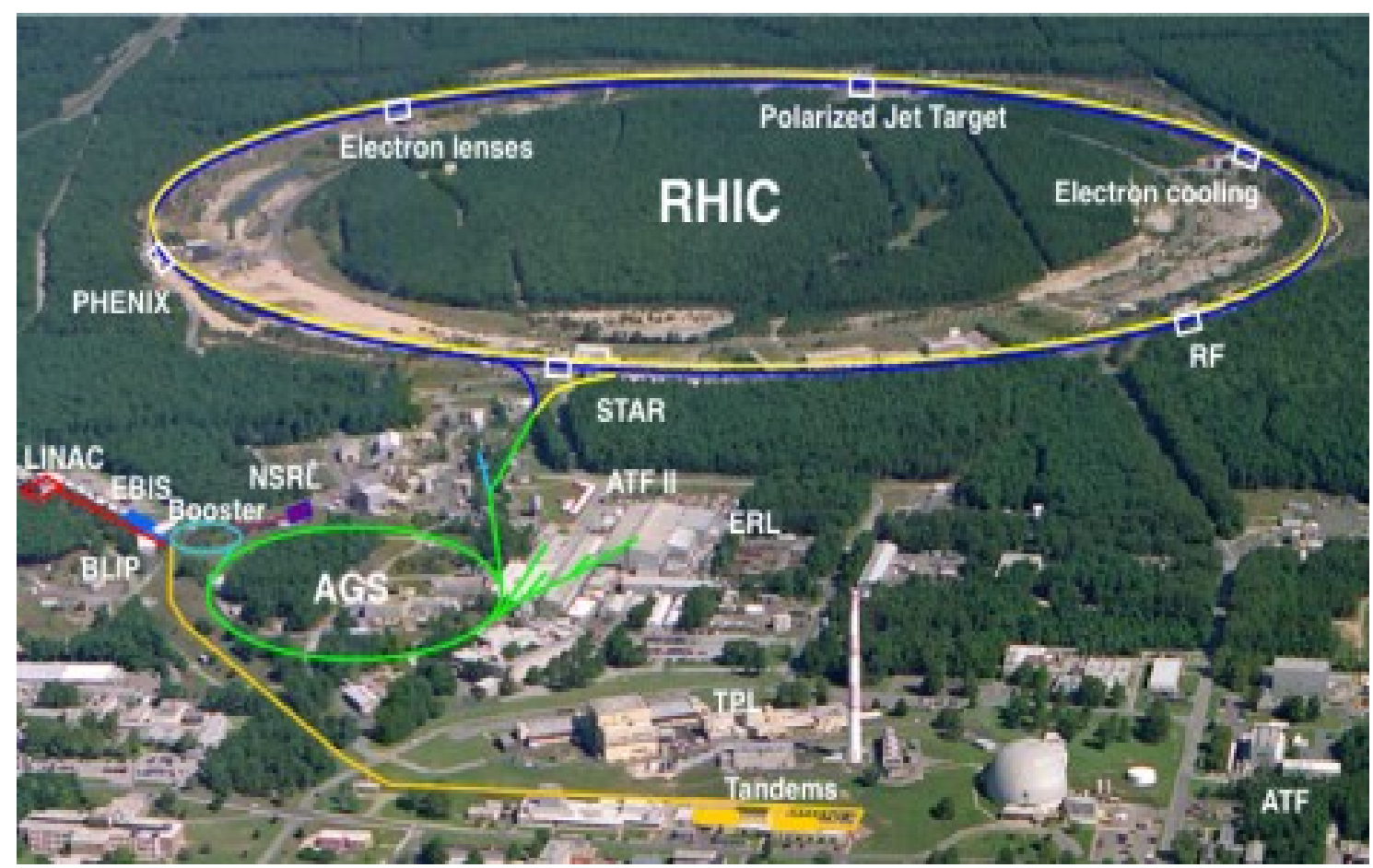

Figure 2 Areal view of the hadron accelerator chain on the BNL site shows the $3.8 \mathrm{Km}$ RHIC Ring

Table 1 Comparison between Ring Ring and Linac Ring E-RHIC Options

\begin{tabular}{|l|c|c|c|c|c|}
\hline Comparative Item & Ring Ring & & Linac Ring & \\
\hline $\begin{array}{l}\text { Luminosity } \\
{\left[10^{\wedge} 33 \mathrm{~cm}-2 \mathrm{~s}-1\right]}\end{array}$ & e-Ring & H-Ring & e-Ring & H-Ring \\
\hline Technical Challenges & 2.4 up to 12. & & 1.2 up to 14.4 & \\
\hline Energy (GeV) & Cooling & & e-source, Cooling & \\
\hline CM energy & Up to 18 & 275 & 8.3 & 250 \\
\hline $\begin{array}{l}\text { Rms norm. emit- } \\
\text { tance h/v[um] }\end{array}$ & 104.9 & & 91 & \\
\hline Cost estimate \$ & $528 / 68$ & $5.3 / 1.8$ & $64 / 64$ & $1.0 / 1.0$ \\
\hline $\begin{array}{l}\text { Accelerator Tech. } \\
\text { Hadron Cooling }\end{array}$ & RCS + storage rings & & $\begin{array}{c}\text { ERL, recircula- } \\
\text { tion }\end{array}$ & \\
\hline
\end{tabular}




\begin{tabular}{|l|c|c|c|c|c|}
\hline Polarization Retention & under study & & Excellent & \\
\hline High Luminosity & & high current req'd & & $\begin{array}{c}\text { small BM size in } \\
\text { IP }\end{array}$ & \\
\hline configuration & & two rings & & $\begin{array}{c}6 \text { rings or } 2 \\
\text { FFAGs }\end{array}$ & \\
\hline Energy usage \$ & & RF power $>$ LR & & $\begin{array}{c}\text { ERL power sav- } \\
\text { ings }\end{array}$ & \\
\hline Infrastructure & & Major RF upgrade & & \$\$ $<<R R$ & \\
\hline Hadron beam flux & & & $3 X$ LR & & \\
\hline Vacuum System & & more complex & & Less SR to absorb & \\
\hline
\end{tabular}

The decision was made to perform a detailed study of the Ring Ring design for the PreConceptual Design Report but to continue R\&D on critical Linac Ring technologies such as the Polarized e-Source for the potential of substantial cost savings and inhansed operational performance. Section four of this report presents the chalenges, design considerations, development plan, and the status of the polarized e-source development that is proceeding at BNL and SBU.

Table 2 e-RHIC Ring Ring Design Parameters

\begin{tabular}{|c|c|c|c|c|c|}
\hline & & \multicolumn{2}{|c|}{ No Hadron Cooling } & \multicolumn{2}{|c|}{ Strong Hadron Cooling } \\
\hline Parameter & Units & Protons & Electrons & Protons & Electrons \\
\hline Center of Mass Energy & $\mathrm{GeV}$ & \multicolumn{2}{|c|}{100} & \multicolumn{2}{|c|}{100} \\
\hline Beam Energy & $\mathrm{GeV}$ & 275 & 10 & 275 & 10 \\
\hline Particles/bunch & $10^{10}$ & 11.6 & 31 & 5.6 & 15.1 \\
\hline Beam Current & $\mathrm{mA}$ & 456 & 1253 & 920 & 2480 \\
\hline Number of Bunches & & \multicolumn{2}{|c|}{330} & \multicolumn{2}{|c|}{1320} \\
\hline Hor. Emittance & $\mathrm{nm}$ & 17.6 & 24.4 & 8.3 & 24.4 \\
\hline Vertical Emittance & $\mathrm{nm}$ & 6.76 & 3.5 & 3.1 & 1.7 \\
\hline$\beta_{x^{*}}$ & $\mathrm{~cm}$ & 94 & 62 & 47 & 16 \\
\hline$\beta_{\mathrm{y}}{ }^{*}$ & $\mathrm{~cm}$ & 4.2 & 7.3 & 2.1 & 3.7 \\
\hline$\sigma_{x}^{\prime *}$ & mrad & 0.137 & 0.2 & 0.13 & 0.39 \\
\hline$\sigma_{\mathrm{y}}{ }^{\prime *}$ & mrad & 0.401 & 0.22 & 0.38 & 0.21 \\
\hline Beam-Beam $\xi_{x}$ & & 0.014 & 0.084 & 0.012 & 0.047 \\
\hline Beam-Beam $\xi_{y}$ & & 0.0048 & 0.075 & 0.0043 & 0.084 \\
\hline$\tau_{\mathrm{IBS}}$ long/hor & hours & $10 / 8$ & - & $4.4 / 2.0$ & - \\
\hline Synchr. Rad Power & MW & - & 6.5 & - & 10 \\
\hline Bunch Length & $\mathrm{cm}$ & 7 & 0.3 & 3.5 & 0.3 \\
\hline Luminosity & $10^{34} \mathrm{~cm}^{-2} \mathrm{~s}^{-1}$ & \multicolumn{2}{|c|}{0.29} & \multicolumn{2}{|c|}{1.21} \\
\hline
\end{tabular}

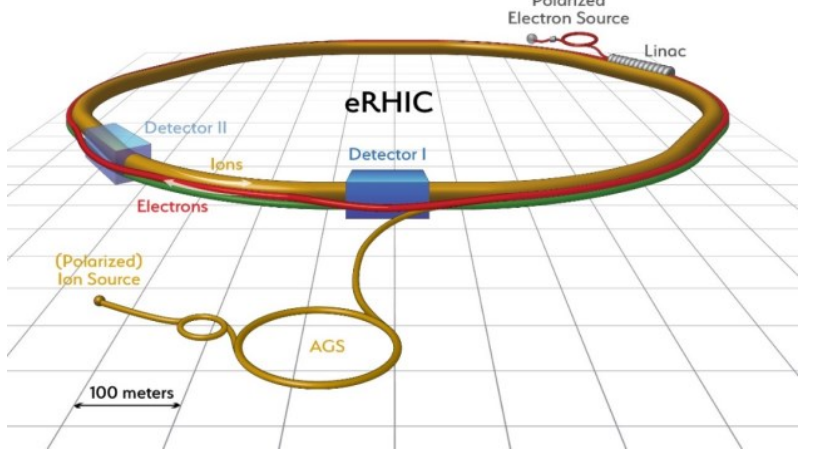

Figure 3

Conceptual Layout of the e-RHIC Design 
Requirements of the Ring Ring are that the two beams must be longitudinally spin polarized in collisions with $70 \%$ hadron polarization, $80 \%$ electron polarization and all combinations of spin orientations present in one fill with Hadron Polarization Polarized protons with $\mathrm{P}>60 \%$ are already provided by RHIC and its injector chain. A H3 Polarization source will be available soon will require the installation of additional Siberian Snakes to be taken from the Blue Ring.

Electron polarization drives the requirements of the injector chain from source to high energy accelerator. The Storage ring will require full energy injection of polarized bunches. Spin polarization preservation in the Storage Ring will require Spin matching, harmonic orbit control and the choice of tunes near integer resonance will be based on HERA experience

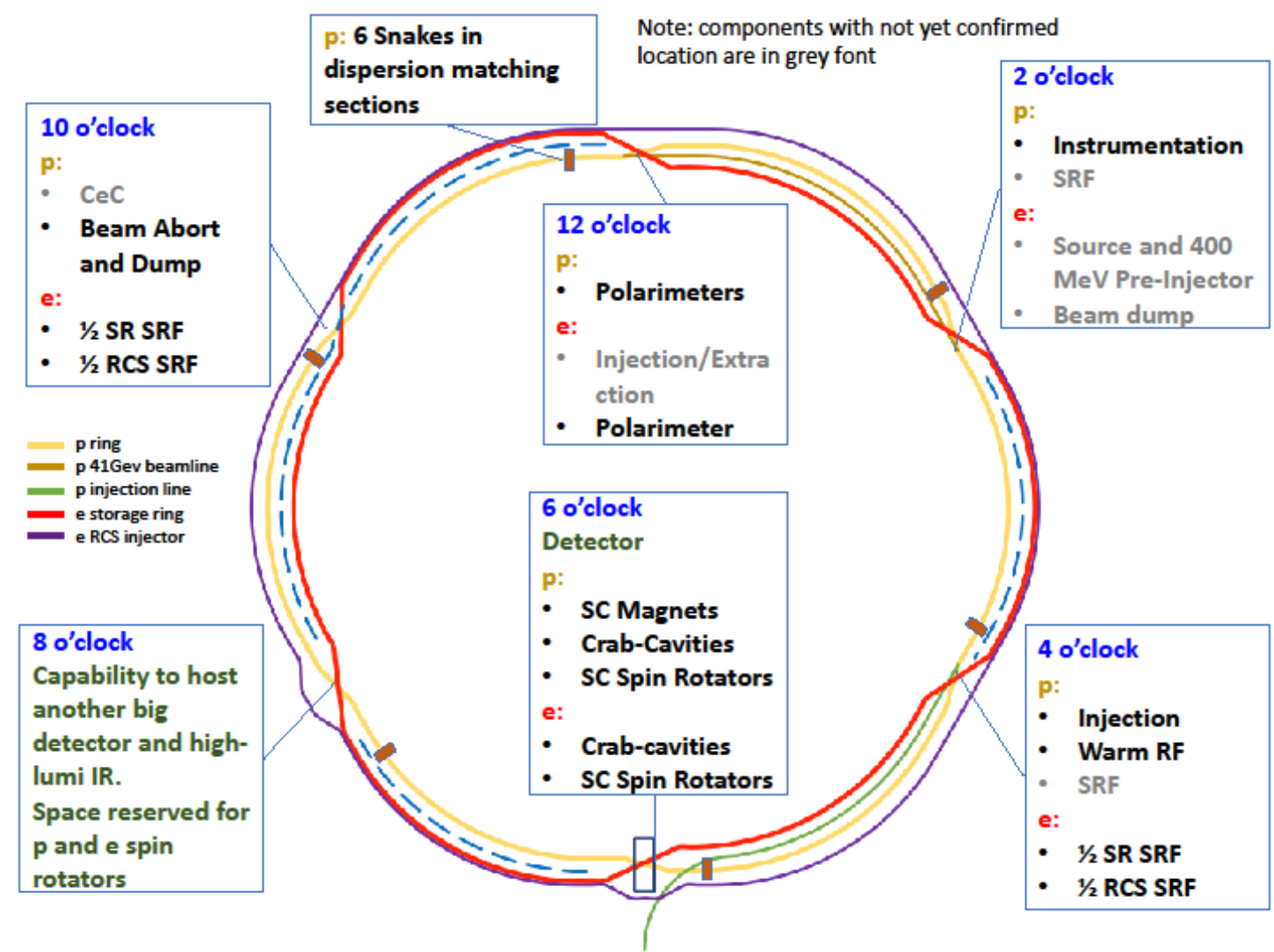

Figure 4 Conceptual Layout of the e-RHIC Ring Ring beam line arc design.

e-RHIC shall use Crab Cavities in the Crossing Angle Geometry at the IR's in an
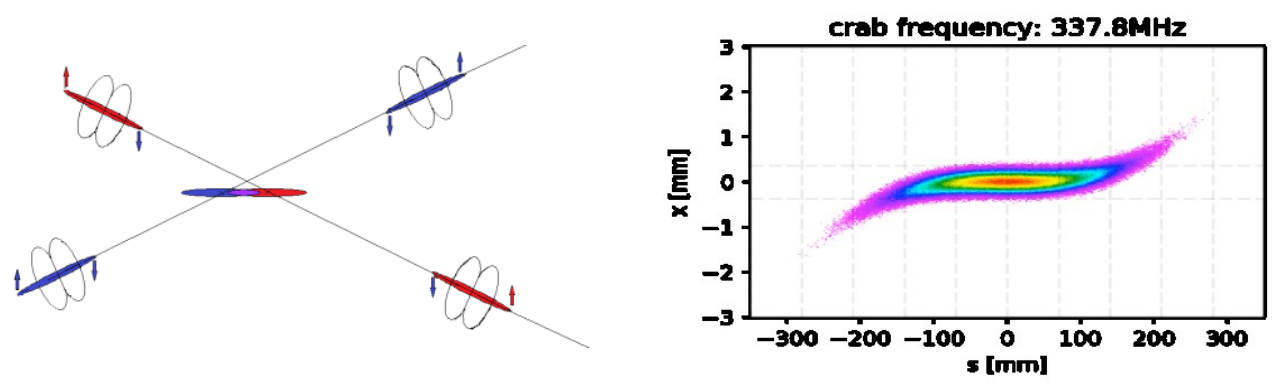

Figure 5 Simulation of crabing beam effects from Higher Harmonic Crab Cavities 
Interleaved arrangement of electron and hadron quadrupoles with a $22 \mathrm{mrad}$ total crossing angle, Beam size in the crab cavity region will be independent of energy, thus crab cavity apertures can be rather small, allowing for higher frequency for a more compact and practical design to manufacture.

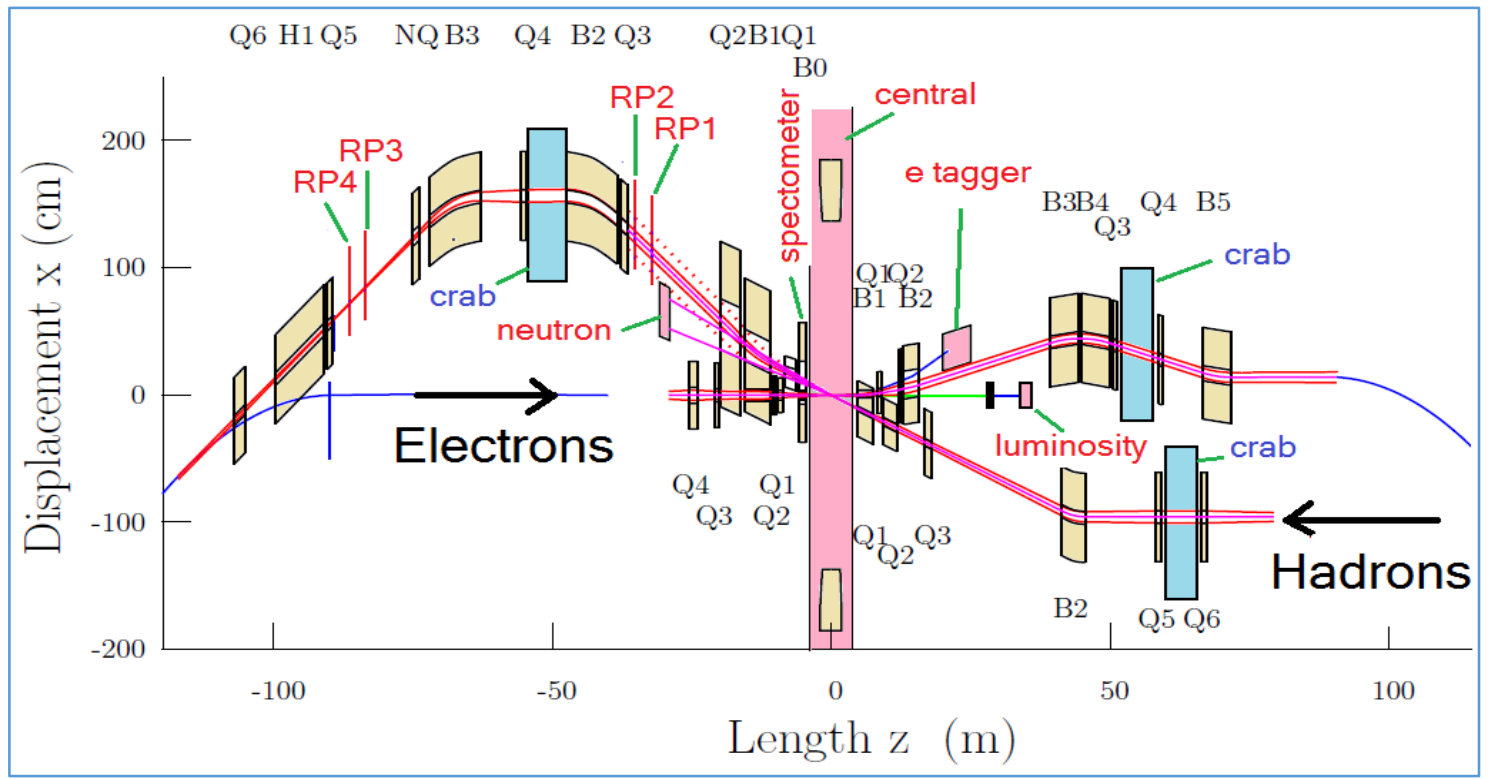

Figure 6 Scematic of the e-RHIC interaction region

Due to the space limitations superconducting quadrupoles will be used for Hadron beams. These quadrupoles will have holes in the return yoke to allow for the electrons to pass through to the interaction region, Active superconducting magnetic shields will be used to isolate the two beam paths.

Figure 7 Prototype Superconducting interaction region Quadrupole.

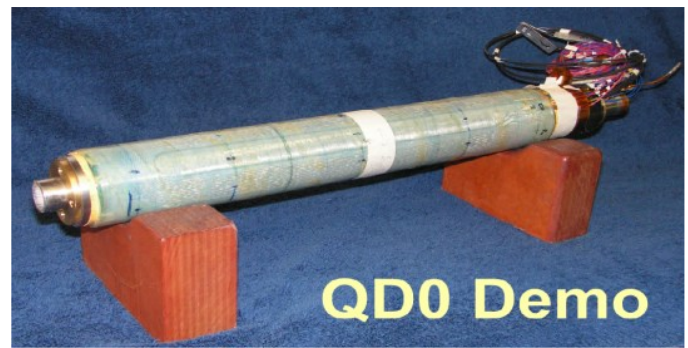

Table 3 Proposed e-RHIC Project Schedule

2017/18: Work out a pre-conceptual design report

2018: e RHIC Design Review

2019: Mission need acknowledged by DOE, critical decision zero (CD-0)

2019-2021: Conceptual design

2021: CD1: site decision

2021-2022: preliminary design project baseline in scope cost, and schedule scope

2022: CD2

2022-2023- Detailed engineering design (final design)

2023: CD-3 Start Construction

2028: CD-4 Start of commissioning and initial operations 


\section{Polarized Gun Development}

One of the critical elements of the EIC is the polarized electron source. In addition to the design of e-RHIC the collider accelerator department is actively developing the Eleacron source for e-RHIC. Figure 8 depicts the solid state physics model of the photo cathode and the use of strained super lattice GaAs

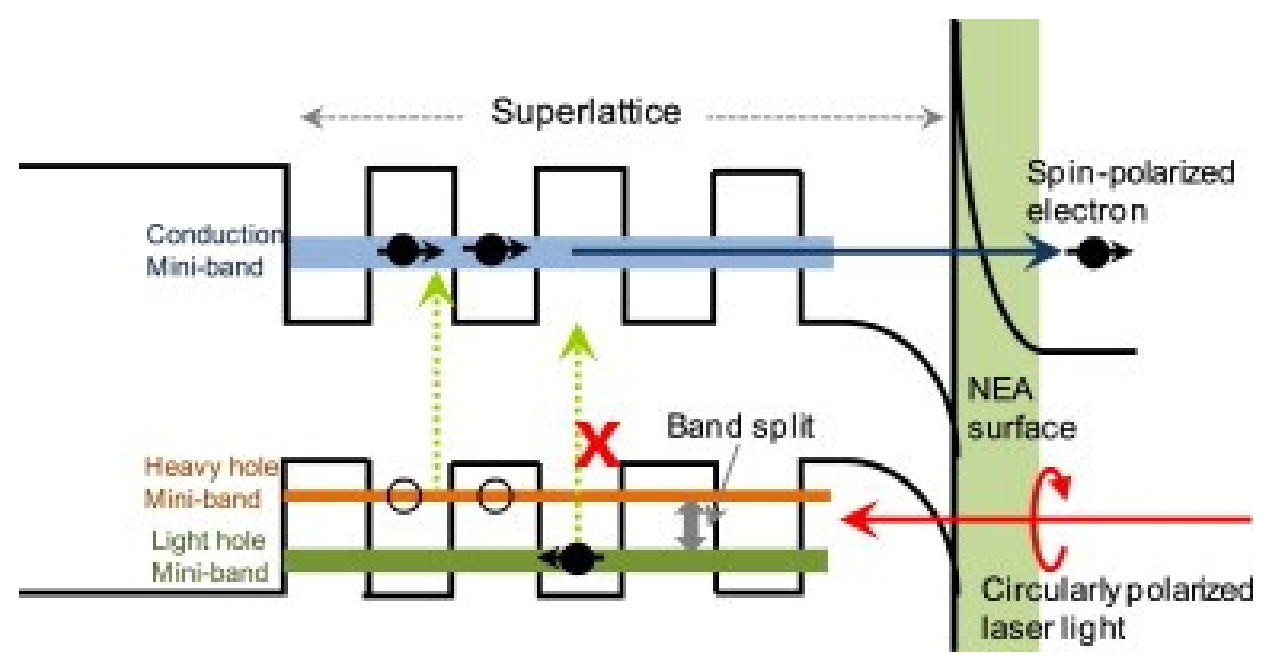

Figure 8 Schematic of the solid state band gap mechinism that produces Spin Polarized electrons.

\subsection{The HV DC photo-gun}

High voltage DC guns have been used as a source of polarized electrons in various accelerator facilities around the world. The Jefferson Lab (JLab) inverted DC gun [2] has generated high average current in $\mathrm{mA}$ class with couple $\mathrm{pC}$ bunch charge while the SLC DC gun [3] has generated $10 \mathrm{nC}$ with several $\mu \mathrm{A}$ 's. Other labs such as MAMI [4], MITBATE [5], Bonn-ELSA [6] or NIKHEF [7] also tested and operated the polarized electron sources, but their results are less than the JLab and SLC results. However, none of them demonstrated high bunch charge $(>100 \mathrm{pC})$ and high average current $(>1 \mathrm{~mA})$ simultaneously.

Recently, two types of DC guns have achieved very high voltage. Cornell [8], KEK [9] and JAEA [10] uses a type of stacked ceramic design feedthrough whereas the Jlab DC guns [11] HV feedthrough are "inverted" where the ceramic is inside the vacuum chamber. Both designs make the field distribution on the ceramic more uniform and help to avoid field emission. Higher voltages in a DC gun are desirable because that helps improve beam quality whilst minimizing ion back bombardment. [12] 
Table 3 Comparason of operating polarized sources and the BNLsource.

\begin{tabular}{|l|l|l|l|}
\hline & SLC & $\begin{array}{l}\text { Inverted gun } \\
\text { (JLab) }\end{array}$ & $\begin{array}{l}\text { Inverted gun in } \\
\text { fabrication (BNL) }\end{array}$ \\
\hline Voltage [kV] & 120 & 350 & 350 \\
\hline Gradient [MV/m] & 1.8 & 3.4 & 4.2 \\
\hline Cathode size [cm2] & 3 & 1.13 & 4.98 \\
\hline Pulse length [nC] & 2 & 0.01 & 1.5 \\
\hline Bunch charge [nC] & $16(9 \sim 12)$ & 0.003 & 10 \\
\hline Average current [uA] & 5 & 4000 & NA (to be measured) \\
\hline Charge lifetime[C] & $\begin{array}{l}<1(20 \% \\
105 s)\end{array}$ & $80(0.1 \%$ loss $)$ & NA (to be measured) \\
\hline
\end{tabular}

4.2 Critical Technical Issues associated with polarized Gun Development.

\subsubsection{Extremely High Vacuum}

Superlattice Gallium Arsenide (GaAs) has many advantages, and is the cathode material of choice to generate polarized electron beam. The GaAs cathode emission surface is coated with an $\mathrm{O}$ (NF3)-Cs monolayer which is very sensitive to gas contamination including Hydrocarbons, oxygen, water and other active gases. The active gases degrade the quantum efficiency (QE) by chemical poisoning [13] [14] while Hydrogen degrades the $\mathrm{QE}$ during beam operation via ion back bombardment [12]. The ions generated by the electron-hydrogen scattering are proportional to the hydrogen pressure. Thus to obtain long lifetime, the gun chamber pressure should be in the $10^{-12}$ Torr vacuum range with Hydrogen being the dominant gas, comprising $99 \%$ of the remaining gas load. BNL has developed pumping and vessel conditioning procedures that routinely demonstrates in the $10^{-12}$ Torr vacuum range in a large complex vacuum system. Further improvements in materials, pumping capacity, and processes have been incorporated into the e=RHIC gun system and these will be tested and evaluated as part of the e-RHIC R\&D program.

\subsubsection{Beam loss}

Beam loss on the beam pipe is the main source of gas and dynamic pressure increase during gun operation. Experience at operating facilities establishes that beam loss should be less than $1.5 \mathrm{nA}$ to achieve a charge lifetime in excess of 1000 Coulombs. High bunch charge, laser transverse halo and longitudinal halo will cause an electron beam halo and induce the beam loss close to the gun. Furthermore, the laser beam profile in both transverse and longitudinal dimensions should be very well defined without pre/post 
pulsing with similar fractional energy outside of the main beam. Instruments designed to study e-beam halo and beam loss have been incorporated into the diagnostic beam line and a unique IR laser system is being developed by BNL and will be used to investigate and mitigate these issues.

\subsubsection{Surface charge limit}

At the Stanford Linear Collider (SLC) experiments with high charge, short bunch length, < $1 \mathrm{~ns}$ (high peak current) surface charge limit was observed. [15] When the peak current is high, this limit leads to a longitudinal current distribution that has a sharp drop due to build up surface charge. High surface doping such as $>5^{*} 10^{19} \mathrm{a} / \mathrm{c}$.c. could reduce the surface charge limit. But this requires tight temperature control during cathode activation. Using the commercial strained super lattice (SL) GaAs sample with doping of 2 3*10 ${ }^{19}$ a/c.c. is a reasonable choice. SL GaAs doping will be further investigated as part of the eRHIC R\&D program.

\subsubsection{Heating effect}

In a beam loss free and ion back-bombardment dominated system, the product of average current $(\mathrm{A})$ and the decay constant $(\tau)$ should be independent of average current. However, when the average current goes above the $\mathrm{mA}$ level, the high power of the laser will heat the substrate leading to cesium loss, which reduces the lifetime even further. $A^{*} \tau$, defined as the fluence life time, is no longer a constant. The GaAs photocathode can usually survive temperatures up to about $90^{\circ} \mathrm{C}$. Thus for high current operations, the cathode needs to be cooled either by cooling media or increased heat capacity. Increased heat capacity has been incorporated into the eRHIC prototype gun design and BNL will also investigate a means to provide active cooling media to the cathode. Both methods will be evaluated as part of the e-RHIC R\&D program.

\subsubsection{Ion back bombardment}

It has been established by Jlab [12] and Mainz [16] that IBB is the dominant effect for lifetime degradation for GaAs when the dynamic vacuum level of the gun is in the $10^{-12}$ Torr scale and Hydrogen is the dominant gas species, given there is minimal beam loss. Both theoretical and experimental work shows that the cathode lifetime is proportional to beam emission area. The following simulations show that most of the high energy ions are focused on the cathode center with a typical radius of $2 \mathrm{~mm}$. While moving the laser off the cathode center will void the ions from DC gap. We can also bias the anode or ion clean the electrodes to prevent the migration of ions generated from downstream beam.

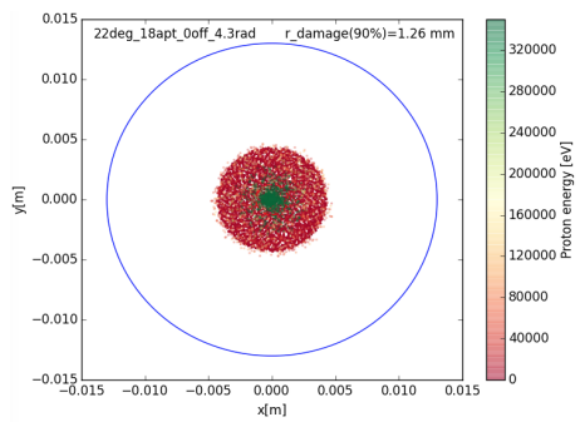

(a)

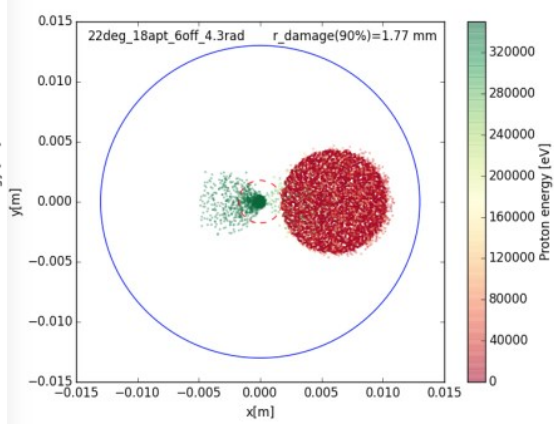

(b)

Figure 9: The back ion distributions on the cathode surface simulation using GPT code. 
The colored dots represent the ions' energy and blue ring is the cathode size. a) Laser on the center. b) Laser off-center.

Improvement of the vacuum in the gun during operation is the most effective way to increase the lifetime. An order of magnitude lower vacuum could give an order of magnitude better lifetime. Other approaches to limit IBB have been to operate the laser off center of the cathode, limiting the active area of the cathode, minimize beam loss due to beam halo etc. These methods have shown improvement and increased the lifetime of the cathode.

\subsection{Gun design strategies and realization}

None of the existing operational guns have solved all the issues listed above. Our gun design considered these issues and has approaches to solve them. The features of our gun are listed as following.

4.3.1 Compared to Jlab cathode, the cathode size is enlarged by a factor of four:

In the ion back bombardment dominated cathode degradation electron source, the charge lifetime could be evaluated by the Equation 1.

$$
L c=\frac{B}{F} \log \left(\frac{B}{E_{\text {end }}}\right)
$$

Where Lc is charge lifetime, $\mathrm{F}$ is the number of ions generated by $1 \mathrm{C}$ of electrons, $\mathrm{B}$ is the total surface Cs bond which is the emission spot density times the cathode area, Eend is the good emission spot area after a certain time of operation. Thus, the charge lifetime is proportional to the cathode area, and inversely proportional to the vacuum pressure and increased by enhancing the gun voltage. Increasing the cathode area is the most crucial improvement in our gun design. Compared to the Jlab gun, the cathode area for our gun is increased by a factor of 4, which increases the effective emission area by a factor of 10 . The anode aperture is also increased accordingly to avoid absorbing the halo electrons and limiting the laser size.

\subsubsection{Addition of a large copper heat sink to the cathode:}

Deposited laser power of greater than a Watt in $\mathrm{mA}$ level operation when isolated by the gun chamber vacuum, will raise the surface temperature of the cathode. [17] In contrast to the JLab stainless steel cathode puck holder, our method is to install a large copper heat sink in contact with the cathode. There will be a large contact surface area between the molybdenum cathode puck and the copper heat sink. Applying strong spring fingers force the contact surfaces together providing adequate thermal conductivity to take advantage of the added thermal capacity to create an effective heat sink.

\subsubsection{Develop a high quality mode-locked fiber laser:}

The laser transverse halo induces beam halo close to the gun. The laser longitudinal halo will induce the beam longitudinal halo which leads to beam loss. Both laser transverse halo and longitudinal halo affect the cathode lifetime significantly. Our method is to use a mode-locked fiber laser to generate high power high quality laser beam. A BNL LDRD is supporting this laser development. This laser has already generated a $2 \mathrm{~W}, 780 \mathrm{~nm}$ beam. The next step is laser shaping and to push to higher power with stable operation. 


\subsubsection{Increase beam pipe diameter by $60 \%$ and use $\mathrm{Ti}$ as beamline material}

Besides eliminating the beam halo, another method to reduce the beam loss close to the gun is by increasing the beam pipe diameter and reducing the beamline out gassing rate. In contrast to Jlab's $6 \mathrm{~cm}$ stainless steel beam pipe, our beam pipe is $10 \mathrm{~cm}$ in diameter. It is essential for any high charge beam to pass through the beam pipe. To take advantage of the low outgassing rate of $\mathrm{Ti}$ and easy bake out process, all the beamlines are made of Ti. The Faraday cup is made of Al, which also has a relatively low out gassing rate. [18]

\section{4 eRHIC Gun geometry parameters and applications}

We use the JLab inverted gun feed through design due to its successful history and the use of parts that are available from industry. The electrode size is limited by many practical factors from manufacturing limitations and ease of assembly into the vacuum chamber. The gun electrodes and HV structure are designed by the following rules:

- Maximize the gradient on the cathode.

- For operating at $\mathrm{nC}$ bunch charge, a large gradient on the cathode could avoid space charge effect limits from the peak current and reduce the emittance. High gradient is achieved by optimizing the anode and Pierce geometry.

- The gradient on the cathode electrodes and shroud surface should be no more than $10 \mathrm{MV} / \mathrm{m}$. A well-polished stainless steel typically has field emission threshold at $10 \mathrm{MV} / \mathrm{m}$.

- In the gun design, the high voltage feed through determines the maximum voltage. The HV gap distance is determined by the maximum Pierce nose shape. All part corner curvatures were carefully optimized to reduce the gradient, keeping all welds and contact surface in low gradient areas.

- Minimize the emittance after space charge compensation

The Pierce shape geometry and first solenoid position were optimized to minimize the emittance after space charge compensation.

Table 4: Parameters of the gun

\begin{tabular}{|l|l|}
\hline Parameter name & \multicolumn{1}{|c|}{ Parameter value } \\
\hline Ball diameter & $20 \mathrm{~cm}$ \\
\hline Chamber diameter & $80 \mathrm{~cm}$ \\
\hline Gap distance $(\mathrm{lg})$ & $5.7 \mathrm{~cm}$ \\
\hline Voltage & $350 \mathrm{kV}$ \\
\hline Cathode size & $4.98 \mathrm{~cm}^{2}$ \\
\hline Electrodes angle $(\alpha)$ & 22 degrees \\
\hline Cathode gradients & $3.8 \mathrm{MV} / \mathrm{m}$ \\
\hline Maximum gradient & $9.9 \mathrm{MV} / \mathrm{m}$ \\
\hline Anode radius $(1 \mathrm{la})$ & $1.8 \mathrm{~cm}$ \\
\hline Pumping speed & $35000 \mathrm{~L} / \mathrm{s}$ \\
\hline Space charge limit & $\mathrm{Up} \mathrm{to} 45 \mathrm{~A}$ \\
\hline Anode bias & $3000 \mathrm{~V}$ \\
\hline
\end{tabular}




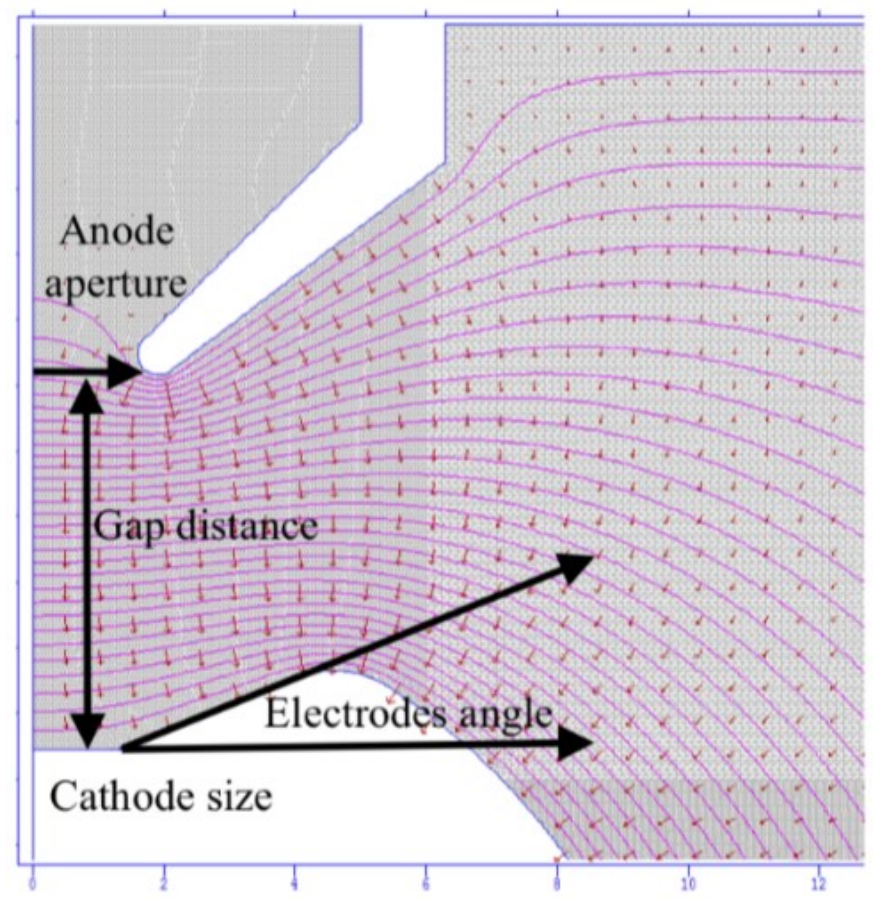

Figure 10: Electro Static Model of the DC gun geometry

The current density is designed to be less than $7 \mathrm{~A} / \mathrm{cm} 2$ which was the space charge limit threshold observed in the SLC experiment. The geometry of electrodes is the spherical cathode shroud with a Pierce shape. Figure 10 shows the gun electrodes with the parameters allowed to be optimized. The optimized parameters are cathode size (Lc), Pierce angle ( $\alpha p$ ) and anode aperture (La). The gap voltage is designed to be up to 350 $\mathrm{kV}$ which is limited by the inverted feedthrough. The optimization for these parameters is carried out following the above rules. The optimized parameters are shown in Table 5. The gun high voltage simulation has been carried out in both 2D and 3D static electrical simulations (Possion, CST and Opera 3D) to make sure all the gradients are lower than threshed.

Because this gun was specifically designed for high current, high charge operation, it could also be used for other purposes such as the Ring-Ring eRHIC electron source and hadron e-cooling. By varying the bunch length, the peak current could be comparable in all three operation modes. Thus, this gun could be used for all three projects by changing different cathode materials and lasers.

After finishing the high current, high charge polarized beam test, we will convert this gun for a $10 \mathrm{nC}$ polarized beam test for Ring-Ring eRHIC electron source and high current test for unpolarized electron beam. This gun will be the test bench for all future eRHIC electron sources R\&D. 


\begin{tabular}{|l|l|l|l|} 
& $\begin{array}{l}\text { L-R polarized } \\
\text { source }\end{array}$ & $\begin{array}{l}\text { R-R polar- } \\
\text { ized source }\end{array}$ & $\begin{array}{l}\text { Hadron cooling unpolar- } \\
\text { ized electron source(CeC) }\end{array}$ \\
\hline Bunch charge $[\mathrm{nC}]$ & 5.3 & 10 & 3 \\
\hline $\begin{array}{l}\text { Average current } \\
{[\mathrm{mA}]}\end{array}$ & $6.3-50$ & $10^{-4}$ & $>200$ \\
\hline Repetition rate $[\mathrm{Hz}]$ & $1.25 \mathrm{M}$ & 1 & $112 \mathrm{M}$ \\
\hline $\begin{array}{l}\text { Bunch length [ps] } \\
\text { from the gun }\end{array}$ & 1000 & 1800 & 600 \\
\hline Peak current [A] & 5.3 & 5.6 & 5 \\
\hline Cathode material & SL-GaAs(DBR) & SL-GaAs & Multi-alkali \\
\hline $\begin{array}{l}\text { Normalized emit- } \\
\text { tance } \\
\text { [mm-mrad] at the } \\
\text { end }\end{array}$ & 40 & No limit & 20 \\
\hline
\end{tabular}

Table 6: Comparison of beam parameters for three projects

4.5 eRHIC electron sources R\&D Plan and program objectives :

1. Complete the BNL inverted gun assembly,

2. Complete and install the gun test system and connect to the beamline

3. Achieve $10^{-12}$ Torr vacuum and condition to above $350 \mathrm{kV}$

4. Install the IR laser and deliver the laser beam with power of 10 Watts on the cathode,

5. Measure the photocathode lifetime as the function of average current and bunch charge and achieve charge lifetime above $1000 \mathrm{C}$ with $5 \mathrm{nC}$ bunch charge and 6.3 $\mathrm{mA}$. Average current.

\subsection{Experimental Gun and Diagnostic Beamline System}

Figure 11 shows the proposed gun testing system. From left to right cathodes are loaded into a load lock and transferred into the cathode preparation chamber, once the cathode are prepared they are checked for quantum efficiency and polarization. The cathodes are then transferred into an extreme vacuum storage chamber. 


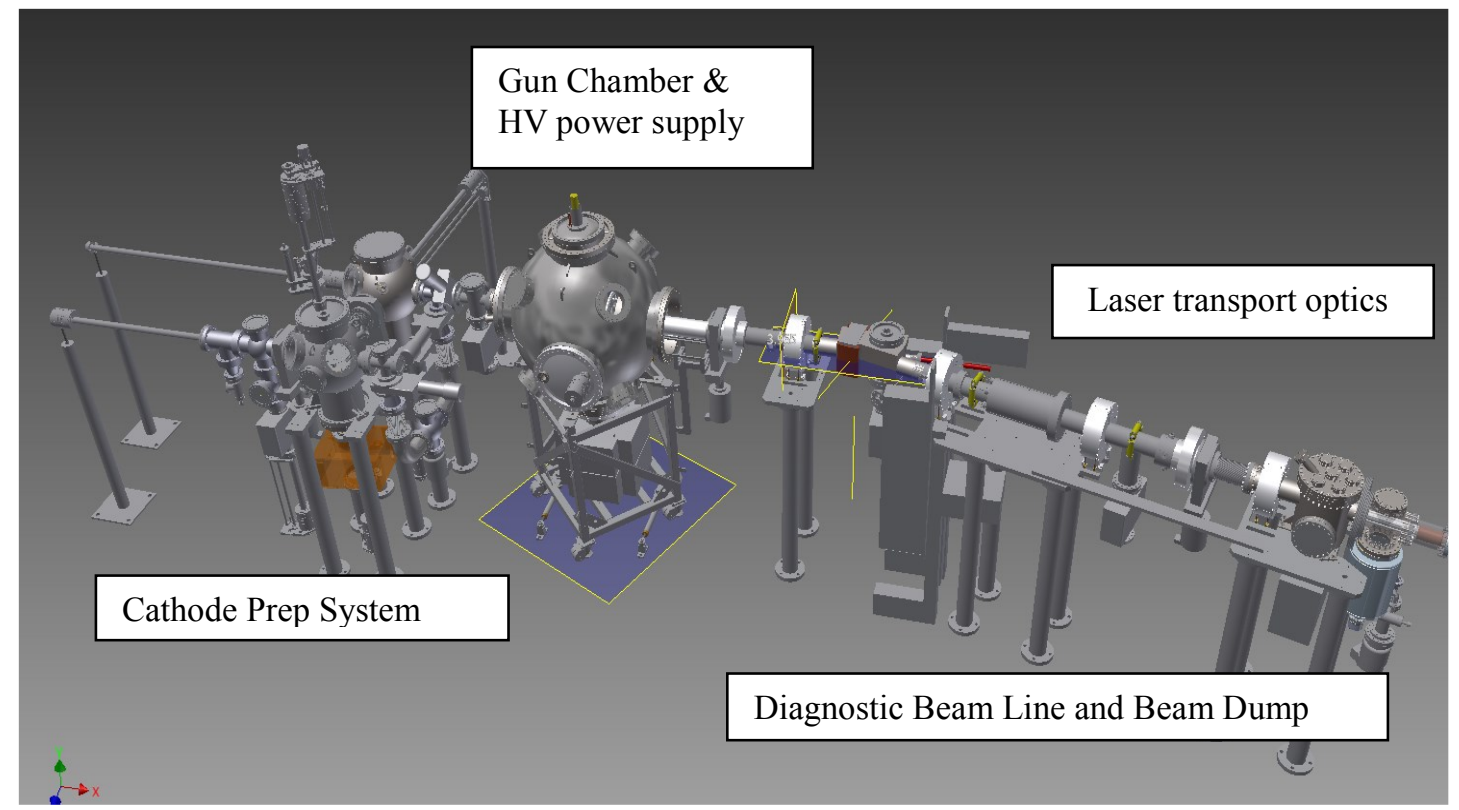

Figure 11: Design of Gun and Diagnostic Beamline

The large spherical chamber is the actual gun chamber. Long manipulators are used to transfer prepared cathodes into the gun chamber to be installed into the cathode shroud of the inverted gun. The laser is directed down the beam line and is imaged onto the cathode. The cathode shroud is charged to high voltage and the resulting photo current e-beam is directed down the beam line. The beam path is bent by a dipole magnet into the diagnostic beam line, to a Faraday cup at the end of the beam Dump.
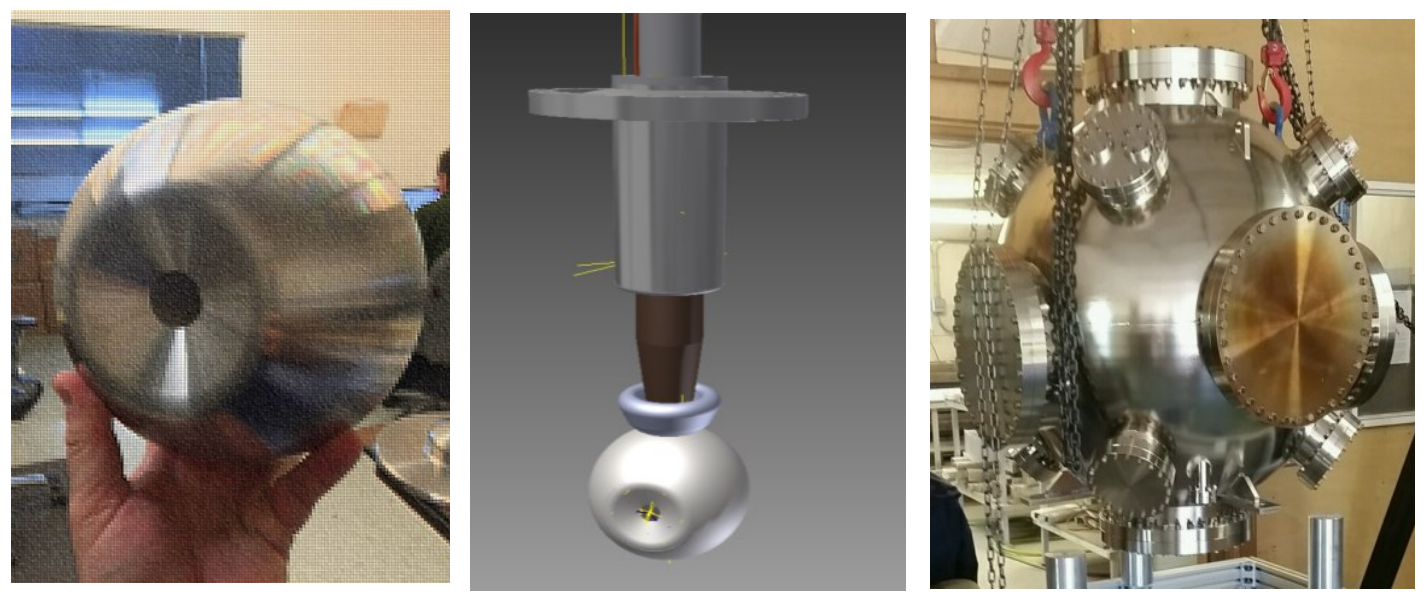

Figure 12: From left to right: Cathode shroud, CAD model of inverted gun HV assy. and DC gun vessel.

Figure 12 shows views of a cathode shroud, a CAD model of the HV components of the inverted gun and the actual gun vessel. Please note the photograph of the gun vessel, in 
previous tests this vessel had achieved extreme vacuum levels into the $10^{-12}$ Torr range with very modest ion and NEG pumping. The chamber and the chamber ports are large enough to accomidate the BNL inverted gun but can be used to test different inverted gun systems. This system can be considered for testing the Ring Ring gun or any DC gun for use in eRHIC. During the period of eRHIC development our one optimised gun design will be used to evaluate all eRHIC DC gun applications. We anticipate this gun test system could be used through the period of eRHIC production testing all the individual DC gun applications. Studies are underway to determine if all the required e-RHIC R\&D can be accomplished using a single gun shroude and and adjustable anode configuration with exchange of different cathode types as being the only varients.

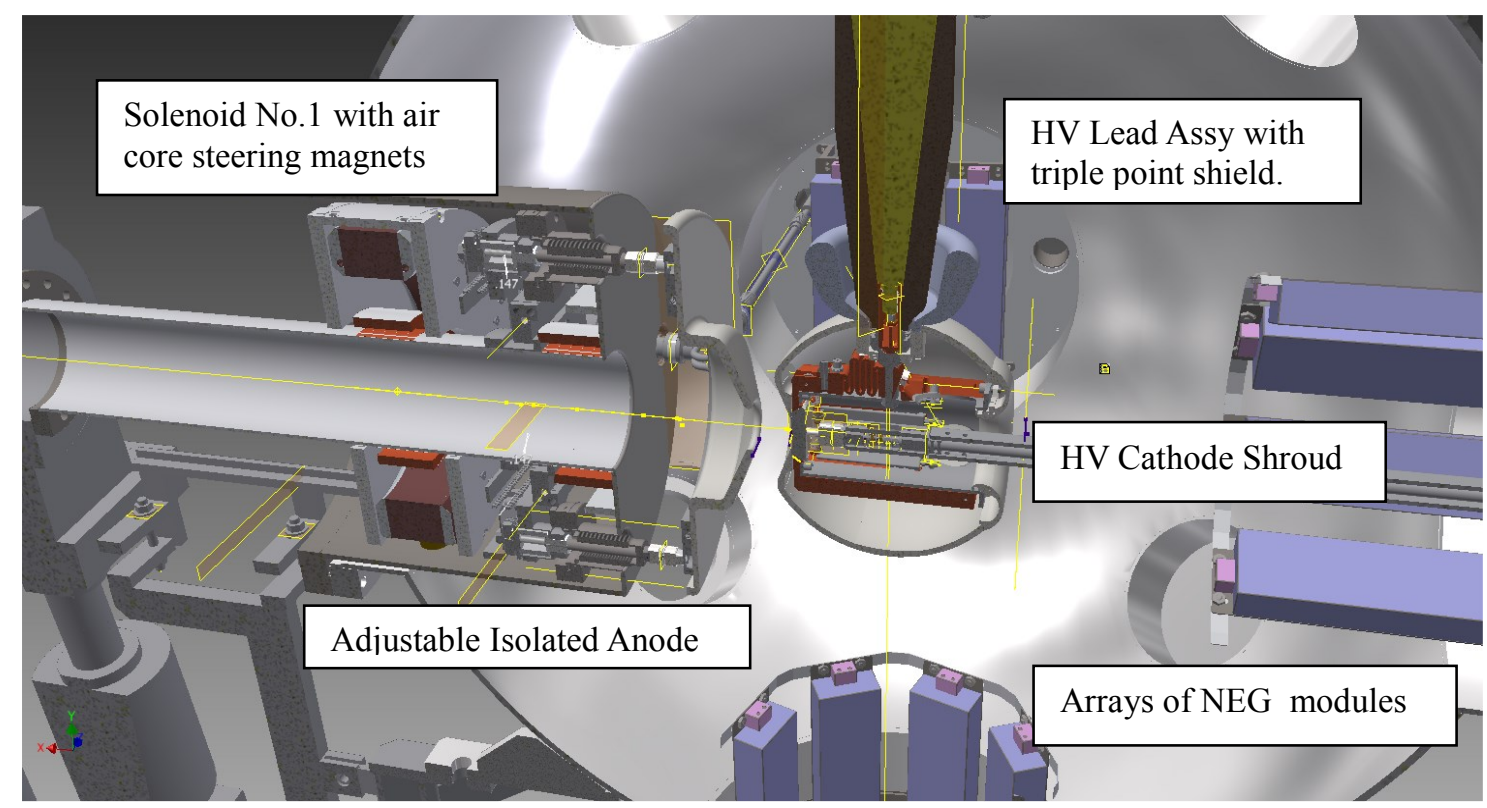

Figure 13: Cross-sectional view of the Inverted DC gun vessel assembly inside the gun vessel. The yellow line is the axis of the beam path. The anode assembly can be biased and adjusted to change the DC gap to optimize gun performance at different voltasges

Figure 13 is a cross section of the gun assembly depicting the round cathode shroud containing a cathode puck that is secured in the center of an electrostatic focusing Pearce shape by a radial set of spring fingers. The cathode is shown at the end of a long manipulator arm that is used to transfer the cathode into and out of the gun vessel. The arm is retracted and locked out of service prior to the application of HV. The brown structure is the ceramic standoff and insulator. A triple point shield is installed between the cathode shroud and the ceramic insulator to minimize the high voltage potential at the interface of the stainless steel shroud and the ceramic. A $127 \mathrm{~mm}$ diameter vacuum fired stainless tube welded to a large rotatable Con-Flat flange assembly is used to position the center axis of the cathode shroud on to the center axis of the gun chamber.

Just ahead of the gun shroud is an adjustable anode assembly. The anode can be biased to minimize the ions entering the gun chamber from the beam line. Air core trim coils are used to position the beam appropriately through the center of the focusing solenoid No. 1 of the diagnostic beam line. Please note the blue boxes in the chamber are NEG pump module assemblies. In total there is about $30,000 \mathrm{Lt} / \mathrm{sec}$ of NEG pump capacity in the main gun chamber. The dark yellow central structure in figure 13 is the high voltage 
feedthrough connector assembly that charges the gun shroud assembly from a high voltage power supply at the opposite end of the high voltage cable. Figure 14 shows a photograph of one of our NEG module assemblies and the high voltage connector that will be used in the gun testing system, We plan to have the capability to condition the gun up to $400 \mathrm{kVolts}$ to provide adiquate headroom for relible operation up to $360 \mathrm{k}$ Volts
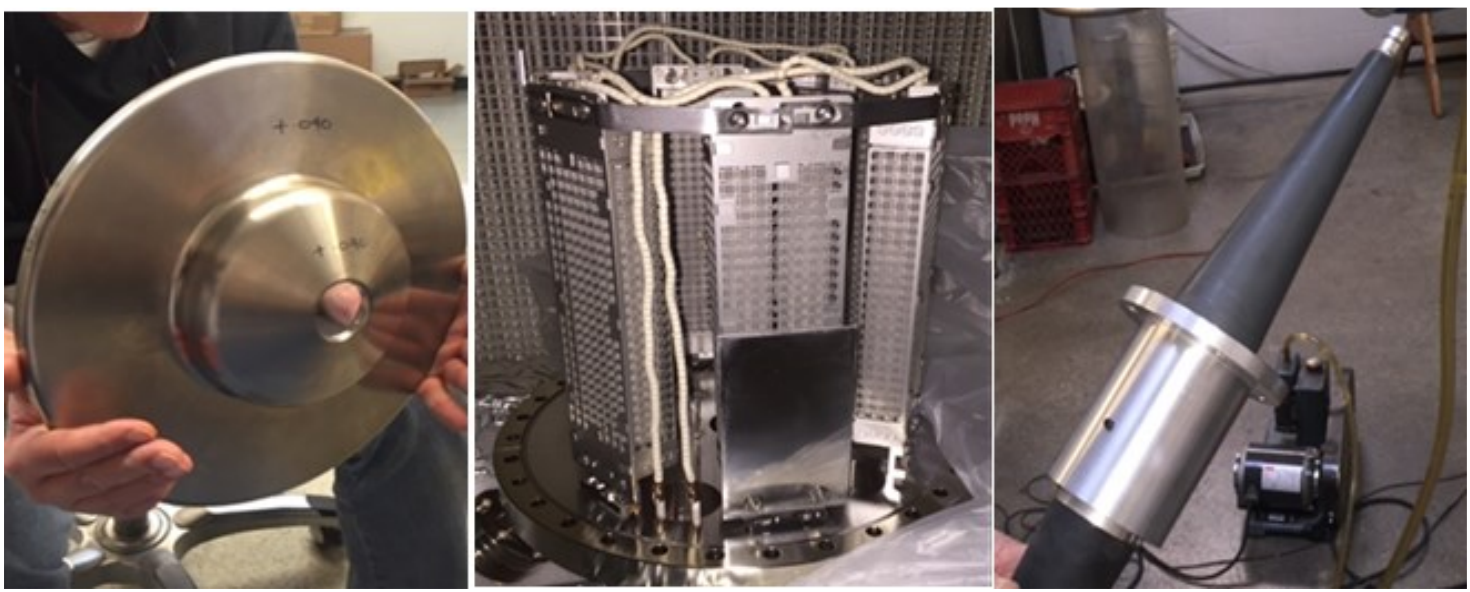

Figure 14: From left to right: Anode, NEG Pump cartridge assembly and $450 \mathrm{KV}$ connector and high voltage cable assembly.

One very important feature of the gun test stand beam line is the differential pumping systems that are designed to maintain at least a 4 decade differential pressure between the vacuum pressure of the gun chamber and the vacuum pressure in the beam stop. This will allow us to produce high current beams and still maintain an extremely high vacuum condition in the gun chamber.

Figure 15 is a Molflow+ simulation of a simplified version of the diagnostic beam line. This illustrates the feasibility to maintain a relatively large pressure differential between the cooled faraday cup in the beam dump and the entrance to the gun vessel whilst maintaining extreme vacuum conditions at the cathode surface. The Faraday cup will be baked and can be electrically biased to create a depressed collector that will minimize the pressure rise caused by the electron beam striking the beam dump.

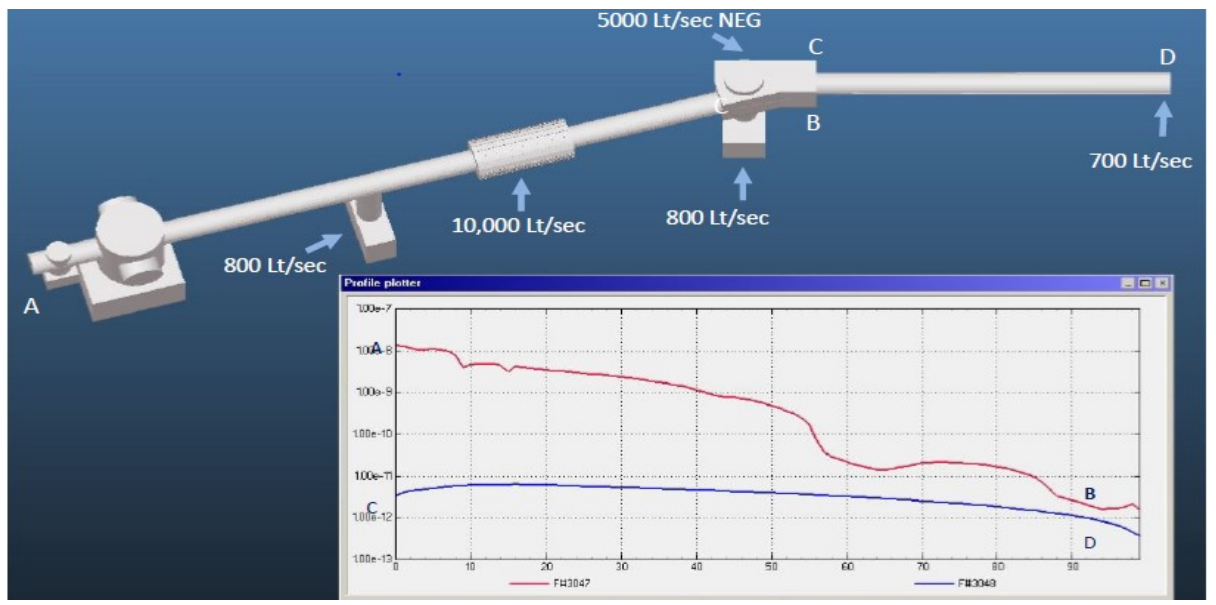

Figure 15: A MolFlow+ simulation of a simplified beam line, performed by SBU grad student Jyoti Biswas predicts that while under beam loading the vacuum system could maintain a four decade pressure differential between the gun vessel and the beam stop. 


\section{In Summary}

The physics case of the EIC is acknowledged not only in the Nuclear Physics community but also stirred the interest of the High Energy Physics Community in particular in the Deep Inelastic Scattering Community, as fundamentally new physics could emerge from an EIC physics Program.

The BNL version of the EIC makes use of the existing RHIC accelerator complex, which constitutes more than $2 / 3$ of the cost of such a facility is called e-RHIC. That promises to be an exciting opportunity for the nuclear and high energy science communities over the next 2-3 decades

The eRHIC design has recently evolved from an ERL based solution which is quite cost effective but has unresolved technical risks to a concept based on an Electron Storage Ring with peak luminosity in excess of $10^{34} \mathrm{~cm}-2 \mathrm{~s}-1$ and energy ranging between $3.0 \mathrm{GeV}$ and $18.0 \mathrm{GeV}$

The accelerator design uses only accelerator components and electron and Hadron beam parameters which have already been demonstrated. An R\&D program is underway to explore cost saving technology.

An important part of the e-RHIC R\&D program is the development of the polarized electron source.

A detailed description of the design considerations and objectives of the source developmental program was presented. The design considerations and a detailed description of the equipment being produced to perform the source development and recent progress were presented.

\section{Acknowledgement}

This work was carried out at Brookhaven Science associates, LLC under Contracts No.DEAC02-98CH10886 with the U.S.DOE.

\section{Bibliography \& References Cited}

[1] D. Geesaman, V. Cirigliano, A. Deshpande, F. Fahey, J. Hardy, K. Heeger, D. Hobart, S. Lapi, J. Nagle, F. Nunes, E. Ormand, J. Piekarewicz, P. Rossi, J. Shukraft, K. Sholberg, M. Shepard, R. Venugopalan, M. Wiescher, and J. Wilkerson, 2015 NSAC Long Range Plan for Nuclear Science (2015).

[2] J. Grames, M. Poelker, P. Adderley, J. Brittian, J. Clark, J. Hansknecht, D. MacHie, M. L. Stutzman, and K. Surles-Law, AIP Conf. Proc. 915, 1037 (2007).

[3] J. E. Clendenin, R. K. Alley, H. Aoyagi, J. C. Frisch, C. L. Garden, E. W. Hoyt, R. E. Kirby, L. A. Klaisner, A. V. Kulikov, C. Y. Prescott, P. J. Saez, D. C. Schultz, H. Tang, J. L. Turner, M. Woods, A. D. Yeremian, and M. S. Zolotorev, in Proc. Int. Conf. Part. Accel. (IEEE, 1993), pp. 29732975.

[4] K. Aulenbacher, C. Nachtigall, H. G. Andresen, J. Bermuth, T. Dombo, P. Drescher, H. Euteneuer, H. Fischer, D. V. Harrach, P. Hartmann, J. Hoffmann, P. Jennewein, K. H. Kaiser, S. Köbis, H. J. Kreidel, J. Langbein, M. Petri, S. Plützer, E. Reichert, M. Schemies, H. J. Schöpe, K. H. Steffens, M. Steigerwald, H. Trautner, and T. Weis, Nucl. Instruments Methods Phys. Res. Sect. A Accel. Spectrometers, Detect. Assoc. Equip. 391, 498 (1997).

[5] G. D. Cates, V. W. Hughes, R. Michaels, H. R. Schaefer, T. J. Gay, M. S. Lubell, R. Wilson, G. W. 
Dodson, K. A. Dow, S. B. Kowalski, K. Isakovich, K. S. Kumar, M. E. Schulze, P. A. Souder, and D. H. Kim, Nucl. Instruments Methods Phys. Res. A 278, 293 (1989).

[6] M. Eberhardt, J. Wittschen, M. Gowin, W. Hillert, and B. Neff, in AIP Conf. Proc. (AIP, 2007), pp. 1031-1036.

[7] M. J. J. van den Putte, C. W. de Jager, S. G. Konstantinov, V. Y. Korchagin, F. B. Kroes, E. P. van Leeuwen, B. L. Militsyn, N. H. Papadakis, S. G. Popov, G. V. Serdobintsev, Y. M. Shatunov, S. V. Shevelev, T. G. B. W. Sluijk, A. S. Terekhov, and Y. F. Tokarev, 260, 260 (1998).

[8] K. Smolenski, I. Bazarov, B. Dunham, H. Li, Y. Li, X. Liu, D. Ouzounov, C. Sinclair, D. G. Crabb, Y. Prok, M. Poelker, S. Liuti, D. B. Day, and X. Zheng, AIP Conf. Proc. 1149, 1077 (2009).

[9] N. Nakamura, Proc. IPAC2012 TUXB02, 1040 (2012).

[10] R. Nagai, R. Hajima, N. Nishimori, T. Muto, M. Yamamoto, Y. Honda, T. Miyajima, H. Iijima, M. Kuriki, M. Kuwahara, S. Okumi, and T. Nakanishi, Rev. Sci. Instrum. 81, 33304 (2010).

[11] M. BastaniNejad, M. Poelker, J. L. McCarter, J. Hansknecht, K. E. L. Surles-Law, J. M. Grames, M. L. Stutzman, J. Clark, R. Suleiman, and P. A. Adderley, Conf.Proc. C110328, 1501 (2011).

[12] J. Grames, R. Suleiman, P. A. Adderley, J. Clark, J. Hansknecht, D. MacHie, M. Poelker, and M. L. Stutzman, Phys. Rev. Spec. Top. - Accel. Beams 14, 1 (2011).

[13] N. Chanlek and J. Herbert, J. Phys. D ... 47, 55110 (2014).

[14] N. Chanlek, R. M. Jones, J. D. Herbert, L. B. Jones, K. J. Middleman, and B. L. Militsyn, Proc. IPAC 1752 (2010).

[15] M. Woods, J. Clendenin, J. Frisch, A. Kulikov, P. Saez, D. Schultz, J. Turner, K. Witte, and and M. Zolotorev, J. Appl. Phys. 73, 8531 (1993).

[16] K. Aulenbacher, Eur. Phys. J. Spec. Top. 198, 361 (2011).

[17] S. Zhang, S. V. Benson, and C. H-Garcia, Nucl. Instruments Methods Phys. Res. Sect. A Accel. Spectrometers, Detect. Assoc. Equip. 631, 22 (2011).

[18] H. J. Halama and J. C. Herrera, J. Vac. Sci. Technol. 13, 463 (1976). 